\title{
Gas temperature control of a high-temperature gas trial system
}

\author{
Leyao Fan ${ }^{1}$, Chaozhi Cai ${ }^{1 *}$, Di Wu${ }^{2}$, Bingsheng $\mathrm{Wu}^{2}$ \\ ${ }^{1}$ Mechanical and Electrical Engineering Institute, Hebei University of Engineering, Handan, \\ 056038, China, \\ ${ }^{2}$ School of information and electrical engineering, Hebei University of Engineering, Handan, \\ 056038, China, \\ email: caichaozhi1983@163.com
}

Keywords: High-temperature gas, temperature control, time delay, cascade control, time-variant parameters.

\begin{abstract}
This paper introduces the function and the work principle of a high-temperature gas trial system (HTGTS), elaborates the importance of gas temperature control in the system, and provides the mathematical models of the system. According to the problems such as time delay, time-variant parameters, interference and so on exist in the control system of gas temperature; a cascade control strategy for the control of gas temperature is proposed. The simulation is carried out by using different control algorithms for the cascade control strategy of gas temperature. The simulation results show that the cascade control strategy named SDMC-LevfuzzyPID algorithm which proposed in this paper has better control performance than the traditional PID-PID algorithm.
\end{abstract}

\section{Introduction}

Supersonic combustion (SC) is an intense chemical reaction happened in supersonic airflow, and the supersonic airflow is maintained before and after combustion, which is a new field in combustion discipline. At present, research on the SC is mainly focus on the combination with ramjet. SC ramjet is a ramjet in which the fuel is burnt in the supersonic flow. Compared with the traditional ramjet, the SC ramjet has some advantages such as little air pressure loss, higher combustion efficiency and so on. However there are still some technical problems in some aspects, that is to develop an effective fuel injection device and flame stability device with a small loss. The solutions of these problems need to be further studied the supersonic combustion. The high-temperature gas trial system (HTGTS) is a simulation device which is used to study the combustion law of the SC and test the thermal stress and strength of high-temperature specimens, so as to meet the requirement of simulation experiment of high-temperature and large heat flux density. HTGTS overcomes the disadvantages of the existing heating device which consists of quartz lamp and graphite, in the simulation capability and reliability of ultra high temperature. So, the research on the performance of HTGTS has a very important significant in the development of ramjet and the test of the thermal stress and strength of supersonic aircraft.

In HTGTS, aviation kerosene is burnt in supersonic airflow, and the high temperature gas about $2100 \mathrm{~K}$ is produced, then the simulation of high-temperature and large heat flux density in the stagnation region of the specimen can be achieved by acting high temperature gas on the specimen. So the direct performance index of the HTGTS is that the uniform and stable temperature field can be produced or not, and the accuracy of gas temperature control directly reflects the performance of the HTGTS. As is known to all, temperature is a variable belongs to the typical process control, which has the typical characteristics of large inertia, large lag and time-variant, so the accurate control of temperature is hard achieved. Besides, the temperature field in the HTGTS is produced by the intense chemical reaction between high-speed airflow and aviation kerosene, therefore, there are uncertainties and outside interference in the system, which make the temperature harder to be controlled. So the application of the traditional control method for temperature control is difficult to achieve satisfactory results. Although the development of intelligent control in recent years has brought the dawn to process control, but its theory is not perfect and theoretical study is more than 
the actual application. So it is urgent to design a control algorithm to achieve the precise control of gas temperature.

In the aspect of temperature control of combustion system, temperature control of boiler steam is widely studied. Zhang et al achieved the temperature control of superheated steam by using cascade neural PID control method [1]. Moradi et al realized the high precise control of boiler steam by using the optimal robust minimum-order observer [2]. Li et al used a back-propagation neural-network PID controller with an immune genetic algorithm to overcome influences of steam temperature caused by time-delay, inertia and nonlinearities [3]. Dong et al achieved the steam temperature control of steam generator by using saturated output-feedback dissipative control [4]. There are few related literatures at home and abroad about the temperature control of high temperature gas. $\mathrm{Xu}$ et al realized the gas temperature control of a high-temperature multi-phase flow wind tunnel by using genetic algorithm to set the PID parameters and solved the problem of long-setting time for the PID parameters, and obtained good results [5]. In order to solve the problem of strong coupling relationship between parameters in the high-temperature multi-phase flow wind tunnel, LI et al have designed a decoupling control algorithm by combining fuzzy control and neuron control, and the research results show that the control method had a better decoupling control performance and achieved the decoupling control of the high-temperature multi-phase flow wind tunnel [6]. A nonlinear model of gas turbine was established and temperature control of gas was achieved by using a decoupling controller [7-8]. Kim et al studied gas temperature control by using the incremental fuzzy PI controller for the accurate mathematical model of the gas turbine is hard to be established [9].

\section{System Descriptions and Mathematical Model}

\section{System descriptions}

The working principle of the HTGTS is shown in Fig.1; it can be seen from Fig.1 that the system consists of the fuel supply subsystem, the combustion subsystem and the control subsystem. The fuel supply subsystem consists of variable frequency driver (VFD), motor, pump, proportional valve, pipelines, solenoid valves, gear flowmeter, etc. It adjusts the flow-rate of the aviation kerosene feeding to the combustor. The working procedure of the fuel supply subsystem is as follows: first, it starts the system and fires the igniter, then supplies fuel to the combustor after success of ignition. The combustion subsystem mixes the fogged kerosene with preheated air, burns them, and finally forms the heat air flow at a specified temperature. The control subsystem consists of a programmable logic controller (PLC) and a industrial personal computer (IPC), where PLC is the field controller, and IPC is remote controller.

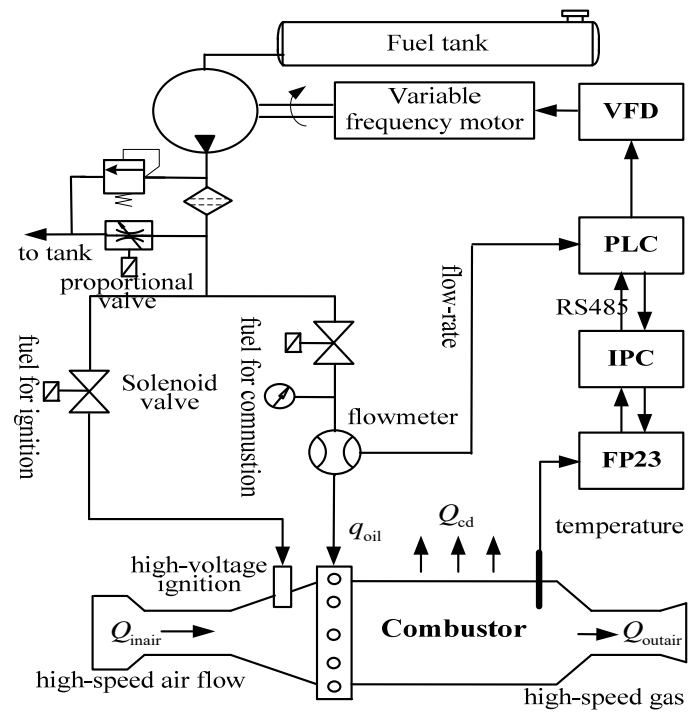

Fig.1 The working principle of the HTGTS 


\section{Mathematical model}

It can be seen from the working principle of the HTGTS that the temperature of the system is generated by the combustion of aviation kerosene in high-speed airflow. However, in the process of experiment, firstly the air speed is fixed, and then the gas temperature is controlled by adjusting the fuel flow-rate, therefore, the control of the gas temperature is mainly governed by the fuel flow-rate of the fuel supply subsystem. So, it is needed to know the mathematical models of the fuel supply subsystem and the combustion subsystem. The flow-rate model of the fuel supply subsystem in the inner loop and the temperature model of the combustion subsystem in the outer loop are given respectively in the following sections.

(1). Mathematical model of flow-rate in the inner loop

It can be seen from the working principle of the fuel supply subsystem that the model of the fuel supply subsystem includes VFD, motor, fixed volumetric pump and fuel circuits. The transfer function between the fuel flow-rate $q_{\mathrm{s}}$ and the VFD input voltage $u$ can be obtained by referring literature [10].

$$
G_{1}(s)=\frac{q_{s}(s)}{u(s)}=\frac{b_{0}}{a_{2} s^{2}+a_{1} s+a_{0}}
$$

where $\quad b_{0}=\frac{1}{60} K_{1} K_{\mathrm{f}} K_{\mathrm{int}} D_{\mathrm{p}} \quad ; \quad a_{2}=\frac{\pi}{30} J_{\mathrm{T}} C_{p} L \quad ; \quad a_{1}=\frac{\pi}{30} J_{\mathrm{T}}+K_{3} L+\frac{\pi}{30} J_{\mathrm{T}} C_{p} R+C_{p} L\left(K_{2}+\frac{\pi}{30} B_{\mathrm{T}}\right) \quad$; $a_{0}=\left(1+C_{p} R \bullet \bullet\left(K_{2}+\frac{\pi}{30} B_{\mathrm{T}}\right)+K_{3} R ; K_{1}=\frac{3 m_{\mathrm{p}}}{2 \pi R_{\mathrm{re}}} K_{\mathrm{f}} ; \quad K_{2}=\frac{m_{\mathrm{p}}^{2}}{40 \pi R_{\mathrm{re}}} ; K_{3}=\frac{D_{\mathrm{p}}^{2}}{120 \pi \eta_{\mathrm{m}}} ; R=R_{\mathrm{L}}+R_{\mathrm{N}} ; K_{\mathrm{f}}\right.$ is the gain between the frequency $f$ and the input control voltage $u$ of the VFD; $K_{\text {int }}$ is the voltage-frequency ratio; $m_{\mathrm{p}}$ is number of the motor pole pairs; $R_{\mathrm{re}}$ is equivalent resistance of the rotor; $J_{\mathrm{T}}$ is the rotational inertia of the motor shaft; $B_{\mathrm{T}}$ is damping coefficient of the motor shaft; $D_{\mathrm{p}}$ is displacement of the pump; $\eta_{\mathrm{pm}}$ is the mechanical efficiency of the pump; $C_{\mathrm{p}}$ is the whole leakage coefficient of the oil circuit; $L=\frac{4 \rho_{\mathrm{oil}} l}{\pi d^{2}}$ is liquid inductance ; $R_{\mathrm{L}}=\frac{128 \mu l}{\pi d^{4}}$ is liquid resistance of the pipeline; $R_{\mathrm{N}}=\frac{\sqrt{2 \rho_{\text {oil }} p_{2}^{*}}}{6 C_{\mathrm{d}} \mathrm{A}_{0}}$ is liquid resistance of the nozzle; $l$ is the length of the pipeline; $d$ is the diameter of the pipeline; $\rho_{\text {oil }}$ is the fuel density; $\mu$ is the dynamic viscosity of the fuel; $C_{\mathrm{d}}$ is flow coefficient of the nozzle; $A_{0}$ is the cross-sectional area of the nozzle; $p_{2}^{*}$ is the operating spout pressure (which is generally a measurement value at starting frequency).

As the gear flowmeter in the actual system has a time delay with $\tau$ seconds, the actual flow-rate $q_{\mathrm{oil}}$ obtained in the controller lags behind the theoretical flow-rate $q_{\mathrm{s}}$. It can be expressed as

$$
q_{\mathrm{oil}}(s)=q_{\mathrm{s}}(s) e^{-\tau s}
$$

Chose the model parameters listed in Table.1, and took them into the equation (1) and corrected the time constants according to large inertia of the flowmeter in the actual system, and then turned unit of the flow-rate to L/min, so the open-loop transfer function of flow-rate in the inner loop can be obtained.

$$
G_{1}(s)=\frac{1155}{1.24 s^{2}+680 s+617}
$$


Table.1 Model parameters of fuel supply subsystem

\begin{tabular}{cccc}
\hline Symbol & Value & Symbol & Value \\
\hline$\rho /\left(\mathrm{Kg} \cdot \mathrm{m}^{-3}\right)$ & $7.8 \times 10^{2}$ & $R_{\mathrm{re}} / \Omega$ & 7.56 \\
$J_{\mathrm{T}} /\left(\mathrm{kg} \cdot \mathrm{m}^{2}\right)$ & 0.054 & $l / \mathrm{m}$ & 12 \\
$B_{\mathrm{T}} /\left(\mathrm{N} \cdot \mathrm{m} \cdot \mathrm{s} \cdot \mathrm{rad}^{-1}\right)$ & 0.045 & $d / \mathrm{m}$ & 0.01 \\
$C_{\mathrm{p}} /\left(\mathrm{m}^{3} \cdot \mathrm{Pa} \cdot \mathrm{s}^{-1}\right)$ & $9.25 \times 10^{-11}$ & $C_{\mathrm{d}}$ & 0.6 \\
$\mu /\left(\mathrm{N} \cdot \mathrm{s} \cdot \mathrm{m}^{-2}\right)$ & $2.34 \times 10^{-3}$ & $m_{\mathrm{p}}$ & 3 \\
$D_{\mathrm{p}} /\left(\mathrm{m}^{3} \cdot \mathrm{r}^{-1}\right)$ & $21.1 \times 10^{-6}$ & $\eta_{\mathrm{m}}$ & 0.87 \\
$A_{\mathrm{o}} / \mathrm{m}^{2}$ & $8.478 \times 10^{-6}$ & $\tau / \mathrm{s}$ & 3 \\
\hline
\end{tabular}

(2). Mathematical model of temperature in the outer loop

Takes the combustion subsystem as a lumped parameter system and according to the law of conservation of energy, the transfer function between the gas temperature and the fuel flow-rate can be obtained by referring literature [10]. It can be expressed as

$$
G_{2}(s)=\frac{T(s)}{q_{\mathrm{oil}}(s)}=\frac{K_{\mathrm{p} 2}}{T_{\mathrm{p} 2} s+a_{1}}
$$

where $a=\rho_{\text {inair }} q_{\text {inair }} c_{\mathrm{p}}+K A_{1} \alpha+\rho_{\text {water }} q_{\text {water }} c_{\text {water }} \beta, K_{\mathrm{p}}=H \rho_{\text {oil }}, T_{\mathrm{p}}=V \rho_{\mathrm{p}} c_{\mathrm{p}} ; H$ is the calorific value of the fuel, $\mathrm{J} / \mathrm{kg} ; V$ is the volume of the combustor, $\mathrm{m}^{3} ; \rho_{\mathrm{p}}$ is the gas density of the combustor, $\mathrm{kg} / \mathrm{m}^{3}$; $c_{\mathrm{p}}$ is the gas specific heat capacity of the combustor, $\mathrm{J} /\left(\mathrm{kg} \cdot{ }^{\circ} \mathrm{C}\right) ; \rho_{\text {inair }}$ is the density of input air, $\mathrm{kg} / \mathrm{m}^{3} ; q_{\text {inair }}$ is the flow rate of input air, $\mathrm{m}^{3} / \mathrm{s} ; K$ is the heat transfer coefficient of the combustor wall, $\mathrm{W} /\left(\mathrm{m}^{2} \cdot{ }^{\circ} \mathrm{C}\right) ; A_{1}$ is the heat transfer area of combustor wall, $\mathrm{m}^{2} ; \rho_{\text {water }}$ is the density of the cooling water, $\mathrm{kg} / \mathrm{m}^{3} ; q_{\text {water }}$ is the flow rate of the cooling water, $\mathrm{m}^{3} / \mathrm{s} ; c_{\text {water }}$ is specific heat capacity of the cooling water, $\mathrm{J} /\left(\mathrm{kg} \cdot{ }^{\circ} \mathrm{C}\right) ; \alpha$ and $\beta$ are the scale factor.

Chose the model parameters listed in Table.2, and took them into the equation (4), so the open-loop transfer function of temperature in the outer loop can be obtained.

$$
G_{2}(s)=\frac{5650}{3.91 s+12.08}
$$

Table.2 The model parameters of the combustion subsystem

\begin{tabular}{cccc}
\hline Symbol & Value & Symbol & Value \\
\hline$H(\mathrm{~J} / \mathrm{kg})$ & $4.29 \times 10^{7}$ & $\rho_{\mathrm{p}}\left(\mathrm{kg} / \mathrm{m}^{3}\right)$ & 1.4 \\
$\rho_{\text {inair }}\left(\mathrm{kg} / \mathrm{m}^{3}\right)$ & 1.293 & $C_{\mathrm{p}}\left(\mathrm{J} /\left(\mathrm{kg} \cdot{ }^{\circ} \mathrm{C}\right)\right)$ & 1117 \\
$q_{\text {inair }}\left(\mathrm{m}^{3} / \mathrm{s}\right)$ & 0.267 & $\alpha$ & 0.8 \\
$\rho_{\text {water }}\left(\mathrm{kg} / \mathrm{m}^{3}\right)$ & 1000 & $\beta$ & 0.01 \\
$q_{\text {water }}\left(\mathrm{m}^{3} / \mathrm{s}\right)$ & 0.0125 & $V\left(\mathrm{~m}^{3}\right)$ & 0.25 \\
$C_{\text {water }}\left(\mathrm{J} /\left(\mathrm{kg} \cdot{ }^{\circ} \mathrm{C}\right)\right)$ & 4178 & $K\left(\mathrm{~W} /\left(\mathrm{m}^{2} \cdot{ }^{\circ} \mathrm{C}\right)\right)$ & 250 \\
$\rho_{\text {oil }}\left(\mathrm{kg} / \mathrm{m}^{3}\right)$ & 780 & $\mathrm{~A}_{1}\left(\mathrm{~m}^{2}\right)$ & 1.5
\end{tabular}




\section{Control Strategy and Simulation}

\section{The overall control scheme}

HTGTS is a system with complex operating conditions, variable parameters and disturbances, for such a system, it is difficult to achieve better control quality by using a single control loop. So this paper proposed a cascade control strategy to achieve the precise control of the gas temperature in the combustor. The overall control scheme of the system is shown in Fig.2; it is a typical cascade control system. It consists of two control loop, the inner control loop of the fuel flow-rate and the outer control loop of the gas temperature. The inner control loop takes fuel flow-rate as the control goal, the fuel supply subsystem as the control plant, and gear flowmeter as the feedback. The outer control loop takes temperature as control goal, the combustion subsystem as control plant, and temperature sensor as feedback. The output of the outer control loop is the input of the inner control loop, thus a cascade control system is formed.

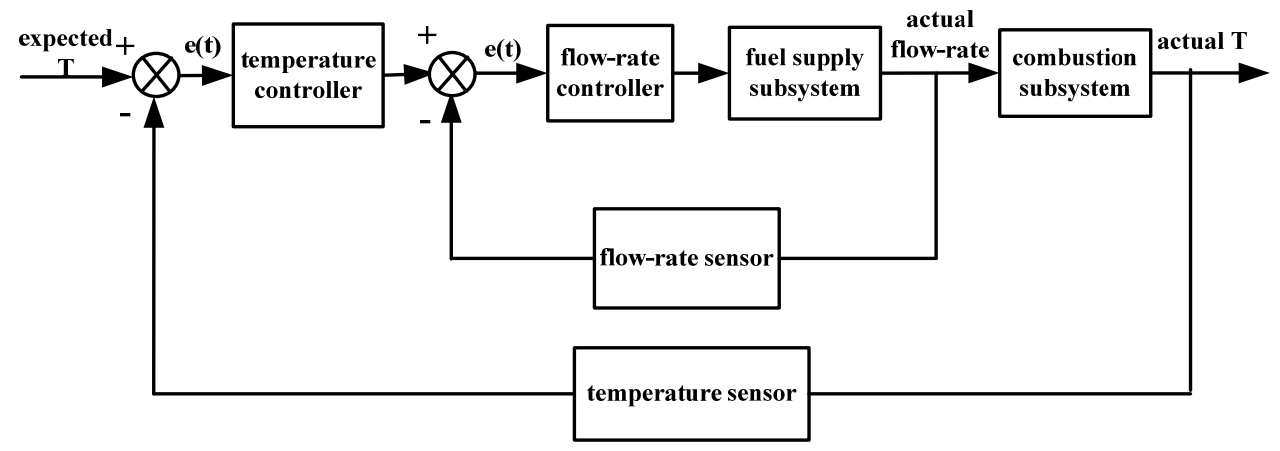

Fig.2. The overall control scheme of the system

\section{SDMC-LevfuzzyPID cascade cnotrol}

Takes the equation (3) as control plant of flow-rate model in the inner loop, and takes equation (5) as control plant of temperature model in the outer loop. The Fuzzy PID predictive control algorithm (LevfuzzyPID) which proposed in reference [11] is used to achieve the flow-rate control in the inner loop, and the sliding-mode predictive control algorithm (SDMC) which proposed in reference [12] is used to achieve the temperature control in the outer loop. Namely the SDMC-LevfuzzyPID cascade control algorithm is formed, and it is used to achieve the simulation control of the gas temperature of the HTGTS. In order to reflect the superiority of the SDMC-LevfuzzyPID cascade control algorithm, the PID-PID cascade control algorithm is adopted to realize a comparative study. A step response from $0^{\circ} \mathrm{C}$ to $800^{\circ} \mathrm{C}$ of the gas temperature is implemented by using the two algorithms in simulation. The simulation results are shown in Fig.3.It can be seen from Fig.3, the two different cascade control algorithms are able to achieve the control of gas temperature, but the SDMC-LevfuzzyPID algorithm is much better than PID-PID algorithm in control effect, namely SDMC-LevfuzzyPID algorithm is better than PID-PID algorithm in aspects of respond quickly and suppresses overshoot.

When the time delay in inner flow-rate model is changed from $3 \mathrm{~s}$ to $5 \mathrm{~s}$ and other conditions are not changed, the simulation results of gas temperature by using the two cascade control algorithms can be found in Fig.4. It can be seen from Fig.4, the SDMC-LevfuzzyPID algorithm is much better than PID-PID algorithm in the ability to overcome time delay. When $0.1 \mathrm{~V}$ interference is added to the inner flow-rate model at $50 \mathrm{~s}$ in the simulation and other conditions are not changed, the simulation results of gas temperature by using the two cascade control algorithms can be found in Fig.5. It can be seen from Fig.5, the SDMC-LevfuzzyPID algorithm is also better than PID-PID algorithm in the ability to overcome interference in the inner loop. Fig. 6 is a comparative result of the two cascade control algorithms in the case of the parameter in the flow-rate model is changed from 680 to 1200 , and other control parameters are not changed. It can be seen from Fig.6, the SDMC-LevfuzzyPID algorithm is also better than PID-PID algorithm in the ability to overcome the time-variant parameter in the inner-loop. 


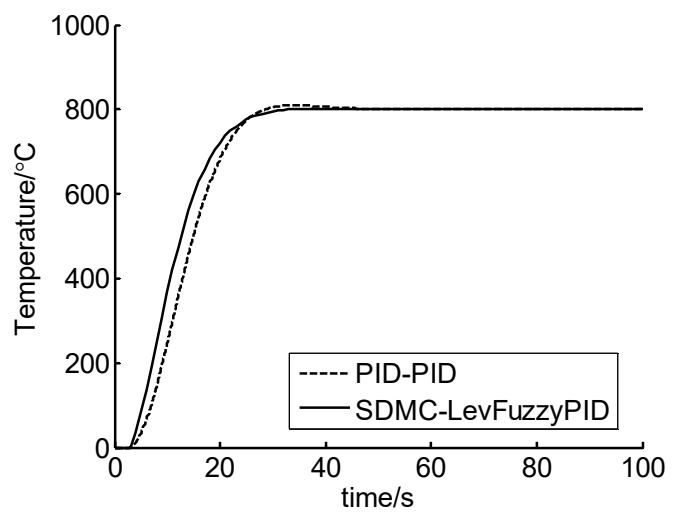

Fig.3 Simulation results of the two control strategies

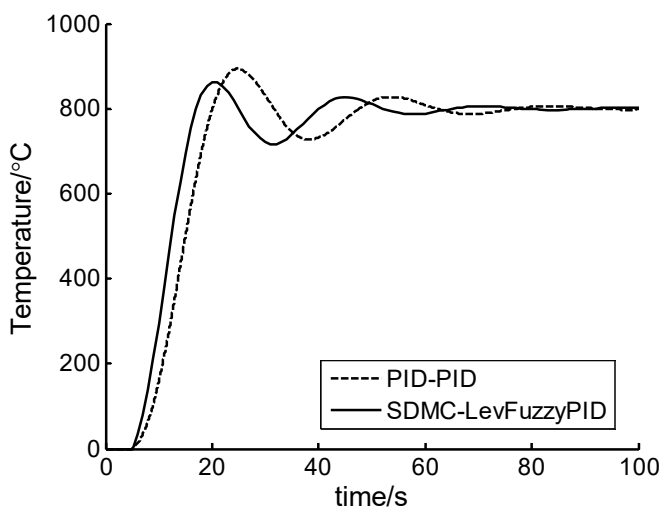

Fig.4 Simulation results when time-delay changed

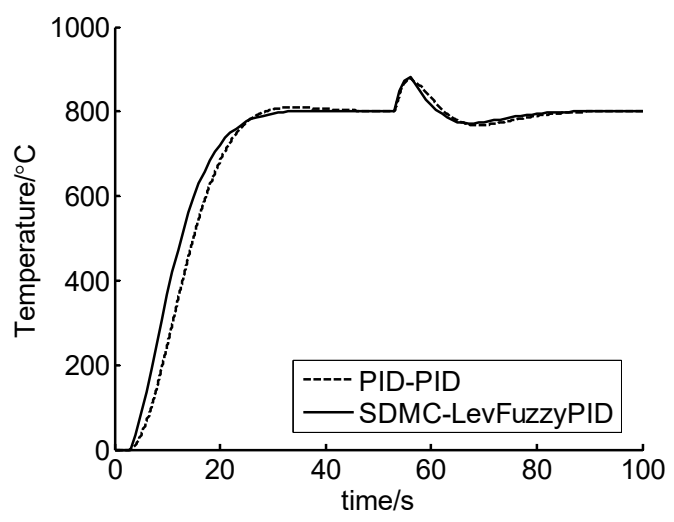

Fig. 5 Simulation results when interference added in system

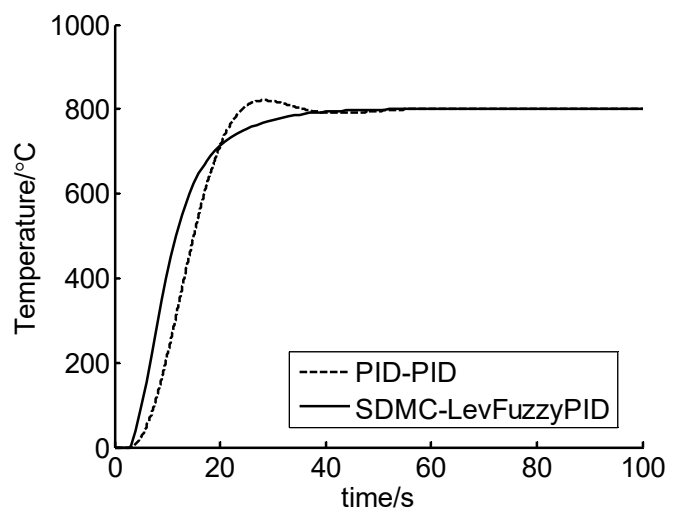

Fig.6 Simulation results when model parameter changed

\section{Conclusions}

This paper introduces the function and the work principle of the high-temperature gas trial 
system, elaborates the importance of control of gas temperature in the system, and provides the mathematical model of the system. According to the problems such as time delay, time-variant parameters, interference and so on exist in the control system of gas temperature; a cascade control strategy for the control of gas temperature is proposed. The simulation is carried out by using different control algorithms for the cascade control strategy of gas temperature. It can be seen from the simulation results, the SDMC-LevfuzzyPID algorithm is much better than PID-PID algorithm in aspects of the ability to overcome time delay, time-variant parameters and interference.

\section{Acknowledgement}

In this paper, the research was sponsored by the Science and Technology Research Project of Hebei Province, China (Project No.QN2015079) and the Nature Science Foundation of Hebei Province (No. F2015402114).

\section{References}

[1] J. Zhang, F. Zhang, M. Ren, G. Hou, F. Fang. Cascade control of superheated steam temperature with Neuro-PID controller, ISA Transactions, 2012, 51(6):778-785

[2] H. Moradi, F. Bakhtiari-Nejad. Improving boiler unit performance using an optimum robust minimum-order observer, Energy Conversion and Management, 2011, 52:1728-1740

[3] H. Li, Z. Zhang. The application of immune genetic algorithm in main steam temperature of PID control of BP network, 2012 International Conference on Applied Physics and Industrial Engineering, 2012,80-86

[4] Z. Dong, X. Huang, L. Zhang. Saturated output feedback dissipation steam temperature control for the OTSG of MHTGRs, IEEE Transactions on Nuclear Science, 2011, 58(3):1177-1190

[5] T. Xu, X. Pu, Z. Yuan. Application of PID parameter setting based on a genetic algorithm in a high-temperature multiphase flow wind tunnel, Journal of Engineering for Thermal Energy and Power, 2010, 25(4):414-417

[6] J. LI, S. Wang, Z. Yuan. Fuzzy PID self-regulation neuron decoupling compensation control in high-temperature multiphase flow wind tunnel, Thermal Power Generation,2010,9(8):23-24

[7] G. Crosa, G. Ferrari, A. Trucco. Modeling and decoupling the control loops in a heavy-duty combustor-turbine plant, presented at the ASME TURBO Expo’95,1995,Paper 95-GT-61

[8] S. M. Camporeale, B. Fortunato, A. Dumas. Dynamic modeling and control of regenerative gas turbines , presented at the ASME TURBO Expo’98 , 1998, Paper 98-GT-172

[9] J, Kim, S. Kim. Design of incremental Fuzzy PI controllers for a gas-turbine plant, IEEE/ASME Trans. Mechatronics, 2003, 8(3):410-415

[10] C. Cai , Y. Li. Undisturbed switching control of fuel flow-rate for a high-speed heat-airflow wind tunnel, Proceedings of the institution of mechanical engineers part G- Journal of Aerospace Engineering. 2014, Vol. 228(12) 2245 - 2254.

[11] Y. Li, C. Cai, K. Lee , F. Teng. A novel cascade temperature control system for a high-speed heat-airflow wind tunnel, IEEE/ASME Trans. Mechatronics 2013; 18(4):1310-1319.

[12] C. Cai Y. Li , S. Dong. Compound sliding mode predictive control for a temperature system of high-speed heat-airflow wind tunnel, Proceedings of the institution of mechanical engineers part CJournal of Mechanical Engineering Science 2014; 228(11):1869-1879. 